\title{
Entre o estranhamento e a carnavalização: considerações sobre as relações de espaço-sujeito em Os transparentes, de Ondjaki
}

Raíra Vasconcelos*

Resumo: Resgatando um universo mítico particular, o romance Os transparentes, de Ondjaki, apresenta uma cidade construída por pessoas comuns em sua sede por (sobre)vivências. Este trabalho tem como objetivo investigar elementos que compõem tal cenário agregador de tradições e inovações. Para isto, utilizaremos de repertório teórico que reflete a categoria de espaço e suas relações com os indivíduos, como a teoria de estranhamento e desautomatização, de Chklóvski, e as ideias de carnavalização de Bakhtin. Assim, entendemos que o romance bebe de tradições literárias e culturais diversas, mas lança-se com inventividade e agudeza de discurso frente ao cenário das literaturas contemporâneas.

Palavras-chave: Tradições. Inovações. Espaço. Indivíduos.

Abstract: The novel Os transparentes, by Ondjaki, presents a city built by ordinary people in its thirst for survival and a particular mythical world. This work aims to analyse elements that set up this scenario and theirs traditions and innovations. Then, I will use a theoretical repertoire that reflects the category of space and its relations with individuals, such as Chklóvski's theory of strangeness and de-automaticization, and Bakhtin's ideas of carnivalization. I understand that the novel returns to diverse literary and cultural traditions, but the text also inserts itself with invention language in the contemporary literary scene.

Keywords: Traditions. Innovations. Space. Individuals.

Resumen: La novela Os transparentes, de Ondjaki, presenta una ciudad construida por gente común en su necesidad de supervivencias. Este trabajo tiene como objetivo investigar los elementos que conforman este escenario que agrega tradiciones e innovaciones. Para esto, utilizaremos un repertorio teórico que refleje la categoría del espacio y sus relaciones con los individuos, como la teoría de Chklóvski, y las ideas de Bakhtin sobre el “carnavalismo". Por lo tanto, entendemos que la novela bebe de diversas tradiciones literarias y culturales, pero se lanza con inventiva y agudeza del discurso frente a la escena literaria contemporánea.

Palabras clave: Tradiciones. Innovaciones. Espacio. Individuos.

\footnotetext{
* Professora Adjunta da Universidade Federal de Pernambuco. Atua na área de Literatura, com ênfase em poesia e literaturas em Língua portuguesa. https://orcid.org/oooo-0001-6791-7946

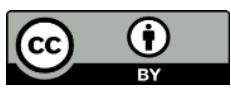

Este artigo está licenciado sob forma de uma licença Creative Commons Atribuição 4.0 Internacional, que permite uso irrestrito, distribuição e reprodução em qualquer meio, desde que a publicação original seja corretamente citada. https://creativecommons.org/licenses/by/4.0/deed.pt_BR.
} 


\section{Introdução}

Teia multicultural e cosmopolita, diversa em seus contrastes e abundâncias, a capital angolana ambienta essa narrativa que aspira tal pluralidade em sua própria tessitura. Os transparentes, romance de Ondjaki, figura entre as principais obras da novíssima literatura de Angola e, traduzida para o espanhol, francês e alemão, exibe-se enquanto obra indispensável para aqueles que pensam o lugar das literaturas em língua portuguesa no cenário internacional.

Publicado originalmente em $\mathbf{2 0 1 2}^{1}$, o livro faz apresentação de Luanda como um espaço heterogêneo e cindido entre povo, poder, sobrevivência e manipulação, por meio do qual seus personagens interagem e dão forma e ritmo às vidas que constroem o enredo. A obra, assim, traz a representação de uma cidade semelhante à metrópole angolana, mas potencializada literariamente em seus elementos sígnicos. Mesmo não exibindo marcações temporais precisas, traz o retrato de um país já independente politicamente, mas que ainda experiencia o tom bélico impregnado no cotidiano das pessoas.

Vale lembrar que Angola, enquanto ex-colônia de Portugal, alcançou sua independência em 1975 e viveu, por mais de uma década, um longo período de conflitos internos entre os grupos paramilitares que disputavam o poder da região. Dessa maneira, refletir sobre este país hoje, mesmo por vias literárias, é visualizar um espaço de riquezas culturais e potencialidades econômicas, mas também, que está em processo de reconstrução do seu tecido social e político. Para entender um pouco mais deste contexto um tanto paradoxal, atentemos ao fato de Angola ter vivenciado um boom econômico entre os anos 2000-2010, mas que luta contra uma desigualdade social dramática, na medida em que, as suas riquezas, advindas especialmente do petróleo, são desviadas das reais necessidades da comunidade nacional (ARENAS, 2019).

\footnotetext{
${ }^{1}$ Editorial Caminho, Portugal.
} 
A referência a esses fatores externos à obra não é dado aleatório, na medida em que percebemos no romance um olhar crítico e reflexivo sobre estes e outros aspectos da sociedade angolana, mas sem se entregar a uma postura investigativa ou sociológica das relações daquele país. Em Os transparentes, compreendemos a palavra literária plurissígnica, mas que anda em laço estreito ao texto cultural que a envolve. Palavra que exibe as histórias dos indivíduos e dos espaços que eles ocupam e constroem por meio de procedimentos narrativos que bebem de uma tradição, ao mesmo tempo que a atualizam. Desvio e diálogo com as fronteiras do gênero e da língua configuram a carnavalização operada nesse texto e exigem do seu leitor a desautomatização do olhar à contemporaneidade da obra.

\section{O edifício e a cidade}

Com uma pluralidade de personagens e ações dispostas em cenários diversos de Luanda, Os transparentes expõe vidas comuns que teimam em persistir num contexto de conflitos políticos e sociais. O romance traz como personagem de destaque Odonato, homem cujo corpo perde, pouco a pouco, a materialidade até ficar transparente. A saga desse personagem é adensada pela busca ao seu filho, CientedoGrã, envolvido em situações de crimes e drogas. Entrelaçado à vida e às questões de Odonato, temos um grande número de outras histórias que se cruzam e se interrompem a depender do foco narrativo, veloz e caótico, como a própria realidade que exibe.

O aparente caos das grandes cidades é deslocado para os espaços apresentados em Os transparentes. Cortes bruscos e retomadas de núcleos pelo olhar do narrador constituem a dinâmica do texto de cruzamento de personagens e situações. Contudo, dentre a proliferação de centros narrativos, o edifício do LargodaMaianga é o principal ponto das ações. Atuando como grande metonímia na obra, o prédio abriga grande parte dos personagens, surge como cenário de ações diversas, além de figurar enquanto espaço social da própria Luanda. 
Conforme pontuam Reis e Lopes (1988), o espaço pode adquirir uma variedade de aspectos e tons, como, por exemplo, a representação em microcosmos, mas que espelhariam realidades mais abrangentes:

Num plano mais restrito, o espaço da narrativa centra-se em cenários mais reduzidos: a casa, por exemplo, dando origem a romances que fazem dela o eixo microcósmico em função do qual se vai definindo a condição histórica e social das personagens [...] Naturalmente que à medida que o espaço vai se particularizando cresce o investimento descritivo que lhe é consagrado e enriquecem os significados decorrentes [...] Sem o teor eventualmente estático do espaço físico, o espaço social configura-se sobretudo em função da presença de tipos e figurantes (v.): trata-se então de ilustrar ambientes que ilustrem, quase sempre num contexto periodológico (sic) de intenção crítica, vícios e deformações da sociedade (REIS; LOPES, 1988, p. 205).

Indo além dos preceitos de deformação social buscado pelos Naturalistas, no romance angolano temos no edifício apartamentos e mundos que confluem entre si. Ao abrigar pessoas em suas distintas realidades, o prédio daMaianga também atua como espaço de alternâncias múltiplas e configura grande parcela do povo angolano. Ali, naquele microcosmo da própria cidade, percebemos, mesmo por meio de uma aparente desordem, uma lógica de comunidade. Em uma das demarcações que surgem como divisões das partes do livro, temos a seguinte passagem que antecede o foco narrativo centrado do prédio:

era um prédio, talvez um mundo, para haver um mundo basta haver pessoas e emoções, chovendo internamente no corpo das pessoas, desaguam em sonhos. as pessoas talvez não sejam mais do que sonhos ambulantes de emoções derretidas no sangue contido pelas peles de nossos corpos tão humanos. a esse mundo pode chamar-se "vida" (ONDJAKI, 2013, p. 69).

São essas pessoas que insistem em sobreviver, em meio a uma realidade pouco justa e humanizadora, e que se permitem sonhar, que dão corpo à obra. Aqui, dentro de cada apartamento, deparamo-nos com os cheiros, as vozes e o ritmo cotidiano daqueles que vivem à margem das instâncias de poder, mas que recebem diretamente as consequências da ganância e dos excessos das altas figuras que administram a cidade. A 
perspectiva crítica da narrativa explora, assim, a distribuição dos espaços enquanto índice da própria configuração daquela cidade, e, indo além dos elementos que poderiam "ancorar a narrativa no real" (REUTER, 2004, p. 59), tal espaço adquire corpulência na obra que almeja mesmo vida própria, atuando quase como qualquer outra personagem do romance. Vejamos a seguinte passagem:

o prédio tinha sete andares e respirava como uma entidade viva havia que saber os seus segredos, as características úteis ou desagradáveis das suas aragens, o funcionamento dos seus canos antigos, os degraus e as portas que não davam para lugar algum. vários bandidos haviam experimentado na pele as consequências desse maldito labirinto com passagens comunicantes de comportamentos autónomos, e mesmo os seus moradores procuravam respeitar cada canto, cada parede e cada vão de escadas (ONDJAKI, 2013, p. 14).

A personificação do edifício comprova a importância deste espaço dentro da narrativa que, com uma aparente vida própria, acorda, respira, adensa a experiência daqueles que por ele andam e recebe o respeito dos seus moradores como um ancião, o velho sábio da comunidade. Por outro lado, aqueles que não conhecem seu domínio perdem-se pelos corredores e andares, confusos em verdadeiros labirintos que perturbam o visitante desavisado. Também é no edifício que temos umas das passagens mais icônicas do romance: a misteriosa água que inunda um dos andares do prédio. Diz o texto:

No primeiro andar, os canos rebentados e uma tremenda escuridão desencorajavam os distraídos e os intrusos a água abundava, incessante, e servia a finalidades múltiplas, dali saía a água para o prédio todo, o negócio de venda por balde, lavagem de roupa e viaturas, AvóKunjikise era das poucas a atravessar o alagado território sem molhar os pés nem nunca ter experimentado a tendência de escorregar - isto é um rio dizia, sempre em Umbundu - só faltam peixes e jacarés (ONDJAKI, 2013, p. 14).

A inundação no primeiro andar do prédio é uma informação recorrente no texto. Como diz o excerto acima, aquela água não tem muita explicação para o seu surgimento e não apresenta uma justificativa para sua permanência ou irresolução do problema. Ao contrário, o que seria inicialmente um evento caótico aos olhos alheios, para os 
habitantes de prédio torna-se em elemento de sustento, agregação e até mesmo insólito. Isso se dá em função de a lógica que costura o cotidiano do lugar escapar à comum. Ou melhor, a ruptura com o perceptual está presente no livro e estabelece uma ordem imaginária que causa sensação de estranhamento ao leitor, neste e em momentos diversos do texto. O tom mágico da presença e permanência da água é aguçado com a voz da personagem mais velha do prédio. Representante de tradições culturais, místicas e linguísticas, a AvóKunjikise parece ser a única que "lê" verdadeiramente o fenômeno das águas, conforme nos sugere o fragmento. O rompimento com uma lógica racional e a aproximação a fabular somam-se ainda a um rompimento com as formas mais tradicionais de escritura romanesca, na medida em que nos deparamos com um esgarçamento do fio narrativo, - de avanços e recuos, como mencionamos anteriormente - que espelha a caoticidade daquele lugar. Sobre a sensação de estranhamento quando lidamos com obras que escurecem, por dizer, as suas formas, vale lembrar a teoria de Chklóvski sobre o tema. De acordo com o autor,

[...] eis que para devolver a sensação de vida, para sentir os objetos, para provar que pedra é pedra, existe o que se chama arte. O objetivo da arte é dar a sensação do objeto como visão e não como reconhecimento; o procedimento da arte é o procedimento da singularização dos objetos e o procedimento consiste em obscurecer a forma, aumentar a dificuldade e a duração da percepção (CHKLÓVSKI, 1976, p. 45).

O processo de desautomatização leitora passa pelo procedimento de liberação de nossas percepções automáticas diante da "verdade" apresentada pela obra ficcional. Aqui, o que nos interessa pontuar, de todo modo, é a forma romanesca inovadora que causa estranhamento, mas utiliza a própria língua do povo. Isto é, complexando a insistente divisão do formalista em automatismo da linguagem cotidiana e vivacidade da linguagem poética, o autor angolano alcança a revitalização do discurso utilizando a fala viva do povo. Tal método lembra-nos a reflexão de Bakhtin (2006) ao postular sobre as relações de espaço-tempo e o trabalho de inventividade do escritor, quando afirma que "o artista interpreta as intenções mais complexas dos homens, das gerações, das épocas, das nações, dos grupos e classes sociais. O trabalho do olho que vê se combina aqui com os mais complexos processos de pensamento.” (BAKHTIN, 2006, p. 225). 
Assim, ao olhar desautomatizado, o teor regenerador daquelas águas não passa despercebido. Além disso, é interessante apontar que o romance é constituído em forma circular: inicia-se com fogo e termina também como fogo, ao elar passagens do começo ao fim da história. No entremeio dessas aparições, entretanto, a água que habita o prédio torna-se símbolo do próprio caráter de coletividade e regeneração daquele lugar. De inundação inconveniente à fonte de vida, a água do prédio opõe-se ao fogo que assola a cidade, ao mesmo tempo em que se liga a ele, exibindo-se enquanto ponto de peregrinação e salvação:

ao primeiro andar, em corrida de procissão coletiva e atabalhoado empurrar de corpos, chegou o grupo todo Edú trazia na mão o seu banco minúsculo e pousou-o de imediato para se sentar perto da mulher, NgaNelucha, que chorava compulsivamente e punha as mãos nos ouvidos para não escutar as explosões que se sucediam, o CamaradaMudo trazia um saco cheio de discos, alguns com capa outros sem nada e deixou o seu corpo cair sobre a água [...] lá fora gritavam vozes humanas as mãos das mulheres atraíram-se, gesto delicado, quase secreto, mais para dividir receios que temperaturas, MariaComForça sentiu que devia invocar outras forças para aplacar as lágrimas da comadre [...] a mão de Maria fez pressão de conforto e Xilisbaba deixouse escorregar encostada à parede, quase deitada sobre o colo da amiga as suas roupas, os seus sapatos, os seus cabelos e a sua alma, tudo ensopado pela água que as protegia do fogo - calma só, comadre...o fogo é como o vento, grita muito, mas tem voz pequenina (ONDJAKI, 2013, p. 391).

O recorte acima exibe a caminhada feita pelos moradores, durante o ápice do incêndio que assolava a cidade, em direção às águas que continuavam inundando o primeiro andar do prédio. Enquanto a cidade queima e as pessoas gritam, no interior do edifício o desespero adquire um sentido de solidariedade e salvação, em que as pessoas se juntam, se apoiam numa espera pela sobrevivência. Atente-se ao movimento das mulheres como procedimento quase secreto, rico de significados, no compartilhamento de emoções e rezas para aquela libertação. Sublinhamos como tal papel quase mítico de proteção é vinculado à ação feminina: aqui, são especialmente as mulheres que manifestam - junto à água, que as envolve os calçados, as vestes e as próprias almas - a carga simbólica de comunidade e agregação. 
Ainda no LargodaMaianga, há outro episódio que rompe com as leis gerais de percepção e exibe um referencial mais distante das realidades concretas e não-ficcionais. Note-se que o discurso do romance é permeado por esta tonalidade poética, lírica, e até certo ponto folclórica da própria vida, em que os signos adquirem seus significados por uma tônica particular que desvia nossa atenção à particularidade desse objeto artístico. Destacamos, assim, o momento do resgate do corpo de CientedoGrã, filho de Odonato. Pai e filho, antes da morte deste último, haviam se desentendido e CientedoGrã jurou não mais voltar ao prédio daMaianga. Depois de morto, o pai teve a incumbência de achar e velar o corpo de seu filho. Como costume, o rito fúnebre seria realizado na casa dos pais, junto com os familiares e amigos. Contudo mesmo depois de morto, o corpo ainda parece dispor de faculdade e força. Vejamos o primeiro trecho, logo que Odonato menciona a ideia de levar seu filho para ser velado em casa:

No preciso instante em que a palavra "casa" foi proferida, o corpo de CientedoGrã, já de si pesado, tombou com força no chão, escorregando das mãos sujas de Odonato e de Paizinho, os três puseram-se a olhar entre si, como quem espreita a gruta do mistério, cada um com o leve pressentimento sabido e a desconfiança oca de que o corpo pudesse ter estremecido por vontade própria, esperaram alguns instantes, deixando o corpo inerte no chão, aguardando um movimento que não aconteceria (ONDJAKI, 2013, p. 317).

A situação de perplexidade dos personagens e de espanto do leitor tornam-se mais expressivas quando o corpo de CientedoGrã chega ao edifício:

Ao passar pelo primeiro andar o defunto tornou-se ainda mais pesado, "é feitiço ou o quê?" perguntou o CamaradaMudo que também havia descido para ajudar, no terceiro andar pararam e tiveram que pousar o corpo, MariacomForça desatara num pranto que acompanhava cada degrau [...] lá em cima AvóKunjikise e Xilisbaba preparavam a sala para receber o corpo do falecido (ONDJAKI, 2013, p. 319).

Como já nos sugere o recorte acima, o corpo a cada degrau no edifício e a cada andar que sobe adquire um peso surpreendentemente maior. Apenas conseguem chegar ao sexto andar, onde localiza-se o apartamento de Odonato, em função do número de moradores que se juntaram à procissão. Contudo, a ideia de feitiçaria, que permeava 
entre as discussões dos moradores, adquire maior justificativa quando o corpo de CientedoGrã ganha demasiado peso que nem mesmo a estrutura do prédio consegue sustentá-lo:

O morto foi pousado com brusquidão sobre a enorme mesa que havia sido deslocada para a cozinha, o chão cedeu ao receber o peso, uma fenda evoluiu desde o canto inferior da principal janela, passou debaixo da mesa, traçou uma linha paralela à zona do lavatório e dirigiu-se à sala como uma cobra que fugisse da luz da cozinha. [...] o chão engoliu CienteDoGrã como se a gravidade se concentrasse num grito que o ordenava a descer todos viram o corpo desaparecer do sexto andar, abrindo um buraco do tamanho estrito do corpo deitado, espreitaram e viram o chão do quinto andar ceder sob um ruído intenso (ONDJAKI, 2013, p. 320).

Como se vê, o caráter mágico da situação - que alguns vão considerar como o insólito do realismo mágico - é inserido no enredo de forma tal que, logo em seguida a uma inicial euforia em função do acontecimento, o sobrenatural é incorporado como elemento integrante àquela comunidade. Como frisamos anteriormente, o aspecto encantatório de um povo em suas mais diversas tradições míticas enreda-se ao romance dando-lhe uma medida inventiva na relação entre indivíduos, os espaços que ocupam e a vida cotidiana. A trivialidade das vidas, portanto, toma torneio de protagonismo ao relevar as falas das ruas, os provérbios e crendices, oferecendo uma visão carnavalizada do mundo. E uma das alternativas narrativas que se somam a estas, diz respeito à configuração dos personagens em enlace com a dinâmica da vida luandense e as idiossincrasias do seu tempo.

\section{Riso e transparência}

Figurando como principal personagem da obra, Odonato atrai para si olhares atentos e assustados dos demais personagens que com ele dividem as cenas, mas também daquele que lê. A transparência do personagem, anunciada desde o título da 
obra, traduz um sujeito que está em completa sintonia com seu tempo/espaço. Odonato, em primeiro lugar, tem a sua transparência como ato de resistência e luta; além disso, traz, em função de sua condição social e física, uma profunda reflexão sobre as transformações da cidade em função da crueza dos tempos; e ainda, tal como percebido no prédio do LargoDaMaianga, é também figura, ou melhor, personificação de um discurso social e crítico disposto no romance.

Percebemos como recurso estilístico a instauração do inesperado e a ruptura com o perceptual enquanto elementos ativos na configuração do romance: presente em momentos diversos do livro - desde os recortes e retomadas narrativas, passando pela pontuação mínima do texto e até mesmo na escolha dos nomes das personagens -, talvez encontrem seu ápice na transparência do dito personagem. Resgatar as fontes populares ao mesmo tempo em que se utiliza de leis de liberdade, se assim poder ser denominado, promove uma aproximação entre esse texto e o pensamento bakhtiniano das formas carnavalizadas de mundo e arte. Vale lembrar, por exemplo, do estudo sobre a obra de Rabelais, quando afirma:

Rabelais influiu poderosamente não só nos destinos da literatura e da língua literária francesas, mas também na literatura mundial (provavelmente no mesmo grau que Cervantes). É também indubitável que foi o mais democrático dos modernos mestres da literatura. Para nós, entretanto, sua principal qualidade é de estar ligado mais profunda e estreitamente que os outros às fontes populares [...]; essas fontes determinaram o conjunto de seu sistema de imagens, assim como sua concepção artística (BAKHTIN, 1987, p. 2).

A questão da cultura popular medieval, enquanto fonte para a produção material do francês, fornece-nos alguns caminhos para compreender determinados procedimentos estéticos de inversão e comicidade encontrados no presente romance. Se pertencem ao carnaval a abolição das relações hierárquicas, a indeterminação de fronteiras espaciais e o caráter de renovação, esses são também elementos da perspectiva narrativa que percebe as peculiaridades da Luanda de Ondjaki. E, como afirma Bakhtin,

[...] o núcleo dessa cultura, isto é, o carnaval, não é de maneira alguma a forma puramente artística do espetáculo teatral e, de forma geral, não entre no domínio da arte. Ele se situa nas fronteiras entre a arte e a vida. 
$\mathrm{Na}$ realidade, é a própria vida apresentada com os elementos característicos da representação (BAKHTIN, 1987, p. 6).

Entendemos, portanto, o carnaval bakhtiniano como a inversão do cotidiano, o convencional às avessas, e enxergamos em Os transparentes uma aproximação com essas premissas de representação, quando o texto burla com as delimitações de arte e vida, ou melhor, como paródia da própria vida ordinária e que traz o riso como um de seus principais signos. Frisamos, contudo, que a paródia carnavalesca se difere do riso negativo e formal da paródia moderna, como assinala ainda Bakhtin:

O riso carnavalesco é patrimônio do povo (esse caráter popular, como dissemos, é inerente à própria natureza do carnaval); todos riem, o riso é "geral"; em segundo lugar, é universal, atinge a todas as coisas e pessoas [...], o mundo inteiro parece cômico e é percebido e considerado no seu aspecto jocoso [...]; por último, esse riso é ambivalente: alegre e cheio de alvoroço, mas ao mesmo tempo burlador e sarcástico, nega e afirma, amortalha e ressuscita simultaneamente (BAKHTIN, 1987, p. 10).

Desta maneira, vemos no romance de Ondjaki o riso burlador e sarcástico, ao mesmo em tempo que se revela como patrimônio daquela realidade estranhamente cômica, mesmo quando nega e amortalha. Assim, a transparência de Odonato que, de um lado, pode gerar a estranheza e o riso, também exibe a negação e a crítica de uma dada realidade. Porém, antes de refletirmos sobre a condição de transparência desse personagem, podemos apontar outras ocasiões em que o cotidiano às avessas parece ser a tônica que alinhava aquele contexto. Um dos episódios mais emblemáticos é a criação de uma igreja, a chamada IgrejaDaOvelhinhaSagrada, numa mistura de fé, escracho e comicidade. Segue um trecho:

- aí reside uma das grandes diferenças da minha paróquia, senhor Esquerdista, e aqui cito Mateus, 25:31: "quando, pois, vier o filho do homem na sua glória, e todos os anjos com ele, então se assentará no trono na sua glória e diante dele serão reunidas todas as nações; e ele separará uns dos outros, como o pastor separa as ovelhas dos cabritos; e porá as ovelhas à sua direita, mas o cabritos à esquerda" [...] tenha calma...eu só queria citar parte das minhas investigações bíblicas, para lhe mostrar algum preparo...era para lhe dizer que a nossa palavra de celebração será outra, não será "amén" - qual será? - Nóe quis desviar a conversa - amééééé! - fez o som sério de uma ovelha que respondesse 
aos chamados religiosos - em homenagem a esse bicho tão sacrificado...proponho um brinde à IgrejaDaOvelhinhaSagrada! amééééé! - responderam em coro os presentes (ONDJAKI, 2013, p. 284).

A igreja que surge de uma necessidade local, bem como da malandragem daqueles que a criam, ainda nasce também por meio da desapropriação de um terreno ocupado por uma família de imigrantes. Os chineses, como são chamados no texto, são representantes da grande fatia da população de Luanda de famílias de imigrantes asiáticos, que estão em território angolano há gerações, mas que ainda permanecem aos olhos de muitos "locais" enquanto como estrangeiros e não-pertencentes àquela sociedade. Vejamos o trecho:

- em princípio saem hoje, não queriam sair os chineses, aluguei aquilo por um ano, já terminou há mais de um mês, e não saem, quando você me disse que estava interessado, fui lá falar com os homens - e não saíram? - você nem sabe o trabalho que aquilo me deu, ameaçaram-me com truques de kung fu, bruce lins do caralho... - e você não mostrou seus dotes de karatê misturados com bassula? - eu não, que eu não tenho idade para isso, deixei-os lá estar quietinhos e voltei no dia seguinte - voltou acompanhado da polícia? - não, voltei acompanhado de uma aká - ah, boa, os chinocas querem brincar com o comando Noé - comando, não, mas há assuntos que só se resolvem com aká47 - os gajos borraram-se todos, não? - cheguei lá, mandei dois tiros pro ar e perguntei onde é que estava o BruceLin, o gajo acagaçou-se e fugiu pelas traseiras - boa, é assim mesmo, afinal nós fomos treinados pelos cubanos (ONDJAKI, 2013, p. 278).

As desavenças e os preconceitos culturais se revestem de comicidade e revelam os laços que constroem e emaranham as relações sociais, como nos exibe o recorte acima, em frisar os apelidos, as referências aportuguesadas e a violência por trás do aparente riso.

Soma-se ainda a tais momentos, um aguardado eclipse com vista privilegiada no território angolano. O evento torna-se grande atração no país, que passa a receber pesquisadores de diversas nacionalidades, como nos revela o segmento a seguir, momento em que cientistas brasileiros estão saindo do aeroporto de Luanda:

- o que é isso aí? - são os óculos do puro enclipse, mais-velho, tem de comprar já para não ser surpreendido, já tá quase a chegar o enclipse - 
e eu vim mesmo para observar o eclipse, sou cientista, sabe? - o brasileiro sorria para o jovem vendedor - então o kota já deve saber, não pode olhar só assim tipo tá a espreitar, o sol não gosta - é, eu sei, deixa eu ver como é esse óculo - são os puros óculos oficiais, mô kota, esses tão mesmo autorizados até pelo governo, eu num distribuo produto só assim à toa, é quinze dólares, mô kota, mas euro também vai - e real? Posso pagar em real? - não, mô kota, de momento não estou a trabalhar com moeda brasileira (ONDJAKI, 2013, p. 270).

O fragmento pode resumir o alvoroço em relação ao eclipse e às tentativas mais diversas de lucrar com o evento. O vendedor informal, que está às portas do aeroporto, comunica-se com o turista/pesquisador brasileiro e oferece aquilo que seriam óculos apropriados e autorizados pelo governo local para apreciar o já "eclipse angolano" (ONDJAKI, 2013, p. 278). Porém, contrariando todas as expectativas e certezas científicas, o eclipse não ocorre. Mas não por uma desventura natural ou outra explicação neste sentido, mas sim, por uma conjuntura política: após desavenças internas, o governo angolano decide cancelar o evento. Diante da incredulidade e pilhéria internacional, o "cancelamento" ocorre, de fato, e o inexplicável, mais uma vez, insere-se na lógica da comunidade. A lógica original das coisas ao avesso, por assim dizer, e as diversas formas de paródia formam o constructo representativo do livro. E o protagonista da obra, Odonato, como dito anteriormente, personifica essa tendência do texto, por (des)corporificar o ilógico e surpreendente, no mesmo instante em que transcende o mero questionamento do verossímil/inverossímil.

O nome do personagem, em primeiro lugar, sugere fragilidade e estreiteza, pois odonato é outra denominação das conhecidas libélulas. Delicadeza e leveza serão mesmo atributos do personagem quando sua transparência se acentua, sendo necessário amarrá-lo a objetos pesados para que não alce voo. Afirmamos no início do tópico que a situação de Odonato também poderia ser entendida como um ato de resistência. Para este entendimento, devemos lembrar que o estado de paulatina transparência é percebido de forma muito consciente pelo personagem, que, além de notar o apagamento de sua materialidade desde o início do processo, decide sustentar tal realidade. De acordo com o texto, a transparência é entendida como fase final de uma sequência de faltas: emprego, dinheiro e alimento. Nesse momento da narrativa, a função referencial torna-se mais saliente, e o discurso social, que está espraiado ao longo 
do enredo, adquire um viés crítico contundente, ao passo em que a atmosfera lírica das reflexões torna o discurso igualmente poético.

A pobreza e as dores da fome de Odonato transformam-se em leveza e libertação com a transparência. A sua condição leva o sujeito a um grau elevado de reflexão sobre as mudanças advindas pela modernidade e espaço ocupado pelo homem nesses novos tempos. Observemos a seção abaixo que aborda a melancolia e o desencanto do sujeito diante da realidade observada:

- o tempo é um lugar que também fica parado - dizia Avókunjikise Odonato não sabia por onde começar mas sempre entendeu que caminhar era um modo de resolver o que ainda não tinha uma clara resolução quis pensar que a cidade era um deserto aberto e embora estivesse cercado de ruídos, e de tantos edifícios, a ideia fez-lhe sentido, um claro sentido o que é afinal um lugar cheio de gente humana que se preocupa tão pouco com o outro?, o que é um lugar cheio de carros com gente solitária buscando atropelar o tempo e maltratar os outros para chegar a casa e cumprimentar apenas a sua própria solidão? [...] "esta cidade é um deserto", pensou (ONDJAKI, 2013, p. 169).

O homem que está em desajuste financeiro e emocional sai pelas ruas da cidade à procura de seu filho, como pontuamos anteriormente. Ao observar a cidade, Odonato inquieta-se diante da crueza e leviandade dos dias e das pessoas que convivem, mas sem estabelecerem laços de empatia e afeto, propriamente. As aflições de um pai prolongamse e incidem sobre o tempo e o espaço que ocupa. Contudo, mesmo com a visão crítica para a realidade que o cerca, há uma conexão do sujeito com a sua cidade. Os elos de afeição e prolongamento podem ser sentidos no seguinte fragmento:

[...] Odonato deixou-se estar longas horas na berma do prédio observando a azáfama de carros circulando pelas artérias vastas ou apertadas da cidade de Luanda um brilho de saudade interna iluminoulhe o coração e o homem cedeu à tentação de abrir sua camisa para espreitar desajeitadamente o seu próprio peito, mas a transparência ainda não permitia que Odonato observasse com os olhos o que lhe invadia as veias - Nato? é o quê? - Xilisbaba estranhou o gesto - é o quê o quê - Odonato fechou a camisa - dores no peito? - dores no coração a sério? - dores no coração de sentir. deixa lá, minha mulher, os médicos já me garantiram, sofro de saudades acumuladas (ONDJAKI, 2013, p. 188). 
É possível estabelecer uma aproximação das artérias da cidade, em suas ruas e luzes, com o próprio peito do sujeito. O homem e o prédio surgem, aqui, enquanto mirante e espelho de Luanda num jogo metonímico de reflexos e contradições. Aquela cidade observada causa profunda melancolia. De forma paralela, é por ela, de uma forma que não se vê, que o homem sente dores de saudade, incluindo "de coisas que ainda não aconteceram" (ONDJAKI, 2013, p. 189). E é nesse híbrido de dor e consciência que Odonato, no caótico dia do incêndio, liberta-se de suas amarras físicas e psicológicas e voa em liberdade. Diz o trecho:

Primeiro preocupado, depois conscientemente mais calmo Odonato viu o alvoroço do galo, de corpo cercado pelo fogo que finalmente invadia seu terraço [...] do bolso esquerdo Odonato retirou um minúsculo papel e, sob um olhar seco de despedida e ternura, escrevinhou umas linhas rápidas para depois se debruçar sobre si mesmo e roer com os dentes caninos o pedaço de corda que o atava ao prédio o galo viu Odonato progredir nos céus, solto, livre, abanando o corpo conforme o vento [...] o amarrotado bilhete que o galo, por falta do que mais fazer, aliada a um certo apetite, debicou, abriu, e visto que a matéria empapada se revelava mole e tragável, acabou por ingerir letra por letra, palavra por palavra (ONDJAKI, 2013, p. 394).

Tendo apenas como testemunha um galo, espécie de mascote dos moradores do prédio, o voo de libertação do sujeito não foi visto nem noticiado pelo seu bilhete. A despedida reflexiva, contudo, nos é revelada no início do romance, na primeira seção divisória do livro, que diz: "acabou o tempo de lembrar/ choro no dia seguinte/ as coisas que devia chorar hoje [do bilhete amarrotado de Odonato]" (ONDJAKI, 2013, p. 8) ${ }^{2}$. As relações do sujeito com seu tempo/espaço extrapolam a um máximo grau que a sua única aparente resolução é a partida, a fuga emancipatória daquele que sente na (ou na ausência de) sua pele os conflitos de seu povo e de toda uma geração.

\section{Considerações finais}

\footnotetext{
${ }^{2}$ Conforme indicado no próprio livro, o bilhete de Odonato faz referência direta a um poema da autora angolana Paula Tavares. Ver Amargos como os Frutos, Editora Pallas, 2011.
} 
Os transparentes figura-se no cerne da contemporânea literatura angolana e fixa o seu lugar no cenário internacional. Através de um texto que traz a inventividade como ponto-guia, Ondjaki carnavaliza as formas e a palavra literária ao mesmo tempo em que resgata tradições e com elas dialoga, promovendo, assim, uma teia de relações culturais no seu romance.

Do prédio no LargoDaMaianga à cidade de Luanda, as relações do espaço com o indivíduo constroem um universo ficcional em laço estreito com a metrópole africana, mas sem perder de vista o tom mágico e insólito que configuram a dicção desse romance. Odonato, enquanto protagonista do texto, figura em si o conflito, a desordem e os vínculos de afeto com esses lugares. A sua transparência pode ser lida como a de uma grande metáfora da condição de degradação e necessária libertação do homem comum diante de um contexto de opressão. A ação de alçar voo sobre as chamas da cidade que sempre lhe envolveu, sugere, por vias da fantasia, a sede de escapar (fugir?) em meio ao caos.

Ler a obra do escritor angolano é entender a máxima poética de que o povo é um inventa-línguas, e que, portanto, a fala das ruas, a cultura do povo e a trivialidade dos dias mais simples se aguçam quando potencializadas pelo olhar do artista.

\section{Referências}

ARENAS, Fernando. África Lusófona: além da independência. Trad. Cristiano Mazzei. São Paulo: Edusp, 2019.

BAKHTIN, Mikhail. A cultura popular na idade média e no renascimento: o contexto de François Rabelais. Trad. Yara Frateschi Vieira. São Paulo: Editora Hucitec, 1987. . Estética da criação verbal. Trad. Paulo Bezerra. São Paulo: Martins Fontes, 2006. CHKLÓVSKI, Viktor. Arte como procedimento. In: OLIVEIRA, Toledo de (Org.) Teoria da Literatura: formalistas russos. Porto Alegre: Globo, 1976. 
ONDJAKI. Os transparentes. São Paulo: Companhia das Letras, 2013.

REIS; LOPES, A. C. M. Dicionário de teoria da narrativa. São Paulo: Ática, 1988.

REUTER, Yves. Introdução à análise do romance. Trad. Bergamini; Arruda; Sette; JouëtPastré. São Paulo: Martins Fontes, 2004.

TAVARES, Paula. Amargos como os frutos: poesia reunida. Rio de Janeiro: Pallas, 2011.

Recebido em 30/04/2020.

Aprovado em 04/08/2020. 